\title{
E-commerce Precision Marketing Based on the Advantages of Big Data Technology
}

\author{
Lei $\mathrm{Li}^{1}$, Zheng Mao', Yuemei Ren ${ }^{1,2^{*}}$ \\ ${ }^{1}$ School of Electronic Information Engineering, Henan Polytechnic Institue, Nanyang, Henan, China \\ ${ }^{2}$ Henan Province Engineering Technology Research Center of IIOT, Nanyang, Henan, China \\ *Corresponding Author.
}

\begin{abstract}
:
The core of big data marketing is to enable online advertising to be delivered to the right people through the right carrier at the right time. This can improve the conversion rate and achieve the effect of precision marketing. Combined with the mature cases involving big data precision marketing of relevant enterprises, this paper analyzes the necessity of big data precision marketing by taking enterprise big data precision marketing as an example. This paper also puts forward the specific implementation ways and methods of enterprises in big data precision marketing. The experimental results show that the method proposed in this paper can unify and integrate multiple sets of user data of different systems by opening up the data islands of various systems within the enterprise. This method can effectively analyze and mine data and label users. This method can carry out precision marketing activities for users through data modeling.
\end{abstract}

Keywords: Big Data Marketing, Online Advertising, Precision Marketing, Data Modeling.

\section{INTRODUCTION}

In recent years, with the increasingly fierce market competition, there are more and more kinds of products or services on the market, and consumers have more and more choices. In the past, consumers' choices were limited and marketers could control the market, but now the situation has changed [1-2]. The biggest challenge in marketing is how to keep pace with the times in the information age. In the traditional era, enterprises and customers usually conduct face-to-face transactions. In addition to knowing a small part of customers' consumption habits, enterprises cannot obtain more detailed information about customers, such as name, address, occupation and so on [3]. At the same time, enterprises often cannot quickly obtain user feedback data because they do not have a perfect customer feedback mechanism. Therefore, enterprises can not carry out one-to-one communication with users, and the marketing costs are high in all aspects [4-5]. But with the advent of the Internet plus era, online shopping has 
Article History: Received: 28 October 2021 Revised: 05 December 2021 Accepted: 10 January 2022 Publication: 28 February 2022

become an indispensable part of people's lives. People are no longer restricted by factors such as region and class. They can master a large amount of information about products, brands, prices and word-of-mouth with the help of the Internet, so they have more choices. The combination of the Internet and the traditional retail industry makes enterprises and customers no longer limited by time and place, and can realize virtual transactions on the Internet platform anytime and anywhere, which not only saves all kinds of costs, but also enables both sides to obtain a better experience [6]. In this era, outside the enterprise, enterprises can use various advertising bidding platforms to operate Internet advertising marketing. Within the enterprise, enterprises have the opportunity to carry out precision marketing with the help of big data technology, which can achieve the effect of precision marketing.

\section{RELATED CONCEPTS AND THEORETICAL BASIS OF BIG DATA PRECISION MARKETING}

\section{Related concepts}

Big data refers to the large volume of data that is difficult to capture, manage and analyze by general software tools, generally in terabytes (TB) [7-8]. The "big" of big data lies not only in the "big capacity", but also in discovering new knowledge and creating new value through the exchange, integration and analysis of massive data. Bring "great knowledge", "great technology", "great value" and "great development", and gradually move towards the new information age of innovation socialization. According to IAB's report on global online advertising revenue in 2020, the main forms of online content marketing for global enterprises in 2020 is shown in Figure 1.

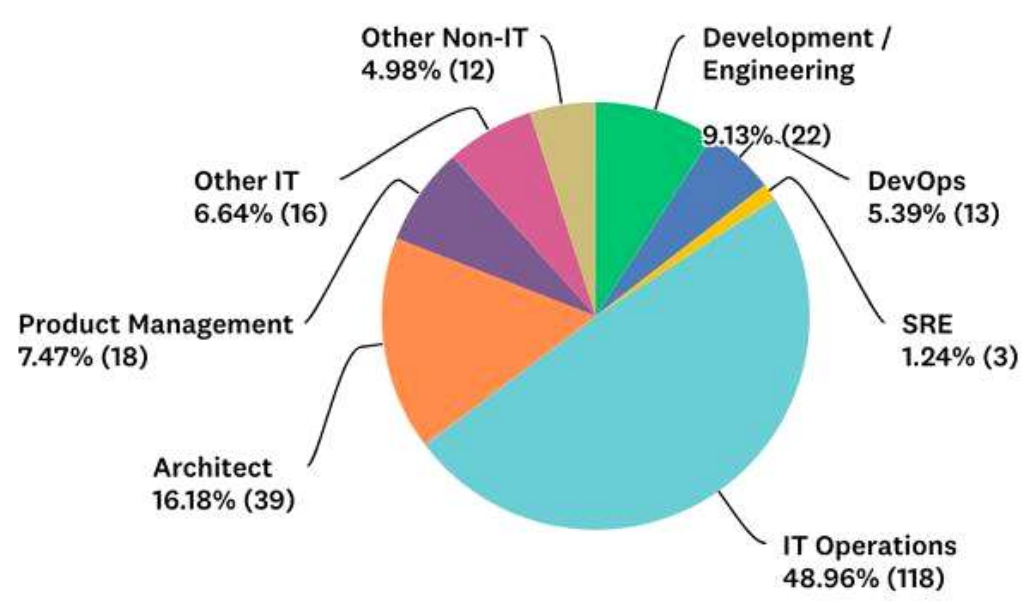


Article History: Received: 28 October 2021 Revised: 05 December 2021 Accepted: 10 January 2022 Publication: 28 February 2022

Fig 1: The main forms of online content marketing for global enterprises in 2020

Generally, user big data refers to two levels of data. One is user anonymous access data, such as user access, view, click, compare, collect, add to shopping cart and other behavior data on the website before purchase. These are unstructured data and stored in the form of enterprise $\log$ [9]. Enterprises need to process it into structured data that is convenient to store in enterprise database. The second is the real name data retained by users on the Internet, such as registration information, purchase records, after-sales records, etc. These data belong to structured data. Enterprise user big data needs to integrate and analyze structured and unstructured data to form a clear user portrait, reasonably predict the user's future behavior tendency and guide marketing in time.

Precision marketing is based on the accurate segmentation and positioning of users, finding the needs and pain points of users, and making appropriate product marketing recommendations to the right users in the right way at the right time, so as to effectively reduce marketing expenses. Precision marketing can be understood as: the scope of precision marketing includes precision data, precision analysis and precision push. "What you want is exactly what I sell". The fundamental purpose of precision marketing is to get rid of the fog, understand users, find user pain points and apply the right medicine to market users [10]. The application of Internet advertising industry in precision marketing is mainly to divide and locate people through RTB, DSP and other methods, and carry out advertising marketing for specific people. On the enterprise e-commerce platform, users are generally accurately recommended through the recommendation of related goods.

For the data summary of multiple data sources, analyze and refine effective data of all dimensions with the help of technical capabilities such as big data collection and analysis. Identify user portraits and predict user behavior trends. Enterprises can output targeted marketing to users, plan one-to-one user communication service system, and optimize user conversion rate. This is big data precision marketing. The purpose of big data precision marketing is to enable product information or services to deliver the right product information to the right people at the right time and in the right way on the premise of effective analysis and identification of users.

\section{Theoretical basis}

Aiming at the problems existing in $4 \mathrm{P}$ theory, Mr. Robert laupunt, an American marketing expert, pointed out the $4 \mathrm{Cs}$ marketing theory corresponding to the $4 \mathrm{P}$ marketing theory of traditional marketing in his article "4P retirement $4 \mathrm{C}$ debut" in 1990. 4Cs marketing theory is 4C marketing theory. It emphasizes that it should be guided by the actual needs of users and reset the four basic elements of marketing mix: consumer, cost, convenience and communication. It emphasizes that enterprises should first put the pursuit of user satisfaction in the first place, and then reduce customers' purchase cost, time, energy and convenience in the 
Article History: Received: 28 October 2021 Revised: 05 December 2021 Accepted: 10 January 2022 Publication: 28 February 2022

purchase process as much as possible. We should not decide how to formulate marketing strategies for users from the perspective of enterprise products, but should formulate marketing strategies based on the actual needs of users and taking users as the center. 4C theory makes enterprises pay attention to all problems from the perspective of users, take the needs of users as the starting point, take the satisfaction of users as the assessment standard, and meet the personal needs of users at the same time. The core of $4 \mathrm{C}$ theory is the planning and design of enterprise product marketing activities based on customers' needs and preferences.

Based on the concept of market segmentation put forward by marketing scientist Wendell Smith in 1956, marketing scientist Philip Kotler finally put forward a new theory. Segmentation, targeting, and positioning. STP theory means that enterprises first subdivide the market, then determine their own target market, and then locate their products or services in the subdivided position in the target market. First, analyze, identify and subdivide users, and carry out precision marketing for users.

\section{CURRENT SITUATION AND EXISTING PROBLEMS OF BIG DATA PRECISION MARKETING FOR W ENTERPRISE USERS}

1.Analysis on the current situation of precision marketing in $\mathrm{W}$ enterprise

Founded in 2014, enterprise W, as a leader in the field of intelligent operation of Internet ecommerce platform, has deeply served hundreds of large enterprises such as telecom operators, banks, large retail groups and large enterprise groups. It also provides Internet solutions for smart tourism of local governments, targeted poverty alleviation of rural special e-commerce and other fields, and helps telecom operators and enterprises in 15 provinces to establish professional new e-commerce platforms based on mobile terminals. Enterprise W is a domestic Internet cloud platform construction and operator specializing in serving large enterprise groups. At present, there are more than $30 \mathrm{~B} 2 \mathrm{C}$ e-commerce platforms in operation. The products operated by the platform cover comprehensive categories such as mother and baby, personal care, food, home and smart appliances. The total number of registered users is more than 80 million and is growing rapidly, but the user activity rate is less than $10 \%$. The primary purpose of this research is to explore a scheme that can improve the activity of platform users and better accurately market users by using big data technology, which has achieved the purpose of reducing enterprise marketing costs and increasing enterprise profits.

At present, the company has applied precision marketing in the following aspects:

Platform users are divided into several categories by using test activities or analyzing users' historical orders. For example, class a users are rich and tend to buy high-quality goods; Class B users are very price sensitive and like to buy discounted goods; Class $\mathrm{C}$ users don't care about the price. They buy everything cheap and expensive. In addition, the user's basic personal information, such as age, education, income, marriage, etc., pushes goods suitable for purchase 
Article History: Received: 28 October 2021 Revised: 05 December 2021 Accepted: 10 January 2022 Publication: 28 February 2022

to such users. Customer purchase information is shown in Table 1

Enterprises generally carry out the following steps: collecting user information, classifying groups, having a strategy for the business model, and collecting feedback on the effect of orders. There are generally three advertising spots on the home page of e-commerce platform, and the commodity advertising groups seen by each group of people are different.

After the customer places an order on the e-commerce platform, the user will then see the "guess what you like" section to conduct cross marketing or upward marketing to the customer. That is, submit the products matched with the product to the customer or recommend such products with higher quality or high profit to the customer to improve the customer's purchase unit price and create revenue for the company.

\section{TABLE I. Customer purchase information}

\begin{tabular}{|l|l|}
\hline Customer & Buy products \\
\hline A & Day cream, facial cleanser, evening cream \\
\hline B & Shampoo, night cream, shower gel \\
\hline C & Facial cleanser, evening cream \\
\hline D & Shampoo, shower gel, facial cleanser, day cream \\
\hline E & Shampoo \\
\hline F & Shampoo, shower gel \\
\hline
\end{tabular}

For the association analysis of Table 1, we first construct the association table between two kinds of goods, as shown in Table 2. Each value in the table represents the number of times that two kinds of goods represented by rows and columns are purchased by a user at the same time.

TABLE II. Association table between two commodities

\begin{tabular}{|l|l|l|l|l|l|}
\hline $\begin{array}{l}\text { X Longitudinal) } \\
\text { Y (Horizontal) }\end{array}$ & $\begin{array}{l}\text { Facial } \\
\text { Cleanser }\end{array}$ & $\begin{array}{l}\text { Sun } \\
\text { frost }\end{array}$ & $\begin{array}{l}\text { Night } \\
\text { Cream }\end{array}$ & Shampoo & $\begin{array}{l}\text { Shower } \\
\text { Gel }\end{array}$ \\
\hline Facial Cleanser & 3 & 2 & 2 & 1 & 1 \\
\hline Sun frost & 2 & 2 & 1 & 1 & 1 \\
\hline Night Cream & 2 & 1 & 3 & 1 & 1 \\
\hline Shampoo & 1 & 1 & 1 & 4 & 3 \\
\hline
\end{tabular}


Article History: Received: 28 October 2021 Revised: 05 December 2021 Accepted: 10 January 2022 Publication: 28 February 2022

\begin{tabular}{|l|l|l|l|l|l|} 
Shower Gel & 1 & 1 & 1 & 3 & 3 \\
\hline
\end{tabular}

According to the set minimum support threshold, calculate the minimum support of each $\mathrm{X}$ (in this example, set the minimum support threshold as 0.3); Support $=0.33$; Support $=0.33$; Support $=0.5$. Others are not listed. According to the set minimum confidence threshold, the minimum confidence is calculated, as shown in Table 3.

TABLE III. Minimum confidence table of $X \rightarrow Y$

\begin{tabular}{|l|l|l|l|l|l|}
\hline $\begin{array}{l}\text { X } \\
\text { (longitudinal) } \\
\text { Y (horizontal) }\end{array}$ & $\begin{array}{l}\text { Facial } \\
\text { Cleanser }\end{array}$ & $\begin{array}{l}\text { Sun } \\
\text { frost }\end{array}$ & $\begin{array}{l}\text { Night } \\
\text { Cream }\end{array}$ & Shampoo & $\begin{array}{l}\text { Shower } \\
\text { Gel }\end{array}$ \\
\hline $\begin{array}{l}\text { Facial } \\
\text { Cleanser }\end{array}$ & $/$ & 0.667 & 0.667 & 0.333 & 0.333 \\
\hline Sun frost & 1.0 & $/$ & 0.5 & 0.5 & 0.5 \\
\hline Night Cream & 0.667 & 0.333 & $/$ & 0.333 & 0.333 \\
\hline Shampoo & 0.25 & 0.25 & 0.25 & $/$ & 0.75 \\
\hline Shower Gel & 0.333 & 0.333 & 0.333 & 1.0 & $/$ \\
\hline
\end{tabular}

2.Problems of big data precision marketing for $\mathrm{W}$ enterprise users

$\mathrm{W}$ enterprise operates the e-commerce platforms of large enterprises and has accumulated a large number of users. A large amount of user purchase information and user data are stored in each platform system. However, each e-commerce platform app operates independently for a long time and has become an "information island". The data and resources of different systems are difficult to be effectively integrated and integrated, resulting in the inability of data integration and analysis. Therefore, it is necessary to break one "information island" and establish a global and centralized data analysis and operation management system, so as to realize the horizontal integration of big data on the whole platform of the enterprise.

The marketing form of B2C e-commerce platform of $\mathrm{W}$ enterprise usually does special activities, second kill, group competition and other activities for all platform users. It has great blindness in marketing decision-making, lacks from the perspective of users, relies too much on past marketing decision-making experience, and the marketing effect is low. W enterprise did not collect and analyze user data to accurately identify users, did not subdivide and locate users from the perspective of users, and did not carry out personalized precision marketing for users.

User anonymous data refers to the anonymous data of consumers on the platform, such as comparing and adding to the shopping cart. It is also an important data basis for user data 
Article History: Received: 28 October 2021 Revised: 05 December 2021 Accepted: 10 January 2022 Publication: 28 February 2022

analysis. If the user's anonymous data is connected with the user's real name data, it will be more conducive to the smooth progress of user portrait and precision marketing activities. At present, w enterprise does not store and analyze the behavior data such as browsing and adding shopping carts of users' anonymous access on the platform, and does not connect the user's anonymous data with the real name data, resulting in incomplete collection of user behavior decision-making data, which may lead to inaccurate judgment of user behavior.

\section{DESIGN OF BIG DATA PRECISION MARKETING SCHEME FOR W ENTERPRISE USERS}

1.Consolidate and integrate data from various data sources

Collect anonymous data left by users on the platform, such as unstructured data such as adding shopping carts before platform registration, data such as users' access logs on the platform, and users' real name data. For example, the user ID, the user's real name, contact information, address, etc. are cleaned and integrated to effectively open up the real name and anonymous data and form a clear and single user view.

The data about users within the enterprise is limited, which only reflects the situation of users within the enterprise, which is not enough in terms of data breadth or depth. Therefore, w enterprise can also consider seeking data sources from outside the enterprise to increase the comprehensiveness of data. First, we can seek cooperative enterprises to let them share the data they have. Enterprise w operates B2C e-commerce websites for operators and other large enterprises. Telecom operators not only master accurate data resources such as customer information, products and resources, but also have a large amount of online data, terminal data and network data. Secondly, third-party marketing service providers can also provide enterprises with useful data about enterprise customers. Data providers can give enterprises access to important information because they collect data from multiple sources in multiple industries. Thirdly, you can use technologies such as data crawler capture to capture data on the Internet, such as search engines and portals, and obtain log and comment data from major social networking sites, forums and other more public websites.

2.Build a big data precision marketing system

After integrating user data, user data from different sources need to be summarized into one system. On the one hand, it is used to clean and store the collected data. On the other hand, it is used to analyze the collected data, identify user attributes, conduct precision marketing for users, and return the user's response data to the marketing system for reference for the next marketing activity. Relying on big data and data analysis applications, the big data precision marketing platform builds a flexible and scalable system architecture, and establishes the whole marketing process management on the basis of customer grouping, customer portrait, customer label library and event marketing rule library. It includes the initiation, implementation, feedback and evaluation of marketing activities to help enterprises realize the data-driven precision marketing 
Article History: Received: 28 October 2021 Revised: 05 December 2021 Accepted: 10 January 2022 Publication: 28 February 2022

model.

First, the structured data, unstructured data and other external information data in each ecommerce platform system of the enterprise are uniformly imported into the data warehousing system for data cleaning and calculation. The data storage system needs to have huge computing power to analyze user data, so as to form user portraits and user labels, so as to provide data support for subsequent precision marketing activities. The marketing automation system is to design certain rules according to the historical order records of the enterprise, and use the constructed marketing automation system to carry out automatic and accurate marketing activities for users for specific user groups.

3. Planning marketing model

Usually, consumers are at different stages of the life cycle and have different demands on enterprises. For enterprises, the user life cycle is divided into these stages, which are user contact stage, user acquisition stage, user development stage, user retention stage and user win back stage. At different stages, users have different awareness of products and enterprises, and the applicable marketing models are also different. W enterprise should establish different marketing models and make different communication strategies at different stages of the user life cycle.

\section{User contact phase, planning user response model}

In the contact stage between the user and $\mathrm{W}$ enterprise, since the user just started to contact the enterprise and has not yet generated consulting or purchase behavior, the enterprise should identify its historical access records at this time. Identify user attributes, identify their potential needs, carry out early marketing promotion, leave a good enterprise or brand impression for users, and have a better feeling for the first interaction.

2.In the user acquisition stage, the user purchase tendency analysis model is adopted

It is how to enable users to register and place orders as soon as possible after w enterprise contacts consumers. At this time, users' portraits are identified based on the user information collected by $\mathrm{W}$ enterprise. This model is used to show consumers the products or services they may be interested in, so that users can place an order and achieve user transformation.

3. In the user development stage, establish the product related sales model

If the user has completed the purchase behavior on the e-commerce platform of $\mathrm{W}$ enterprise, or has purchased frequent customers for many times, how can the user buy other related goods and improve the customer's consumption unit price at this time. The model is used to predict the relevance of consumers' purchase decisions by analyzing the past consumption records of the consumer or similar consumers.

4. Customer churn prediction model is adopted in the user retention stage

For users who are about to lose, w enterprise should screen out users who are likely to lose by using the customer loss prediction model. Analyze user attributes and historical purchase records, analyze and summarize the products or services required by users at the current stage, 
Article History: Received: 28 October 2021 Revised: 05 December 2021 Accepted: 10 January 2022 Publication: 28 February 2022

send targeted product preferential marketing information, retain customers and reduce customer churn rate before customers completely disappear.

5.User win back phase, silent customer activation model

If the customers of $\mathrm{W}$ enterprise sleep or turn to other enterprises or brands, by establishing the model, select the needs they are interested in and carry out customer care marketing, so as to pull the customers back.

\section{CONCLUSION}

Based on the concepts and development status of big data and precision marketing, as well as the mature 4C theory, customer delivered value theory and STP theory in the marketing field, this paper aims at the current marketing problems faced by $\mathrm{W}$ enterprise. Then, according to the relevant enlightenment obtained from relevant case enterprises at home and abroad, we can plan and design the implementation steps and methods of big data precision marketing of $\mathrm{W}$ enterprise.

\section{ACKNOWLEDGEMENTS}

This research was supported by Science and Technology Key Project of Henan Province: Research on Key Technologies of Link Prediction in Complex Networks( No.202102311007), Key Scientific Research Project of Universities in Henan Province: Social Network Link Prediction in the Era of Big Data (No. 22A520026), Funding Program for Young Backbone Teachers of Higher Vocational Schools in Henan Province (Key Technology Research of Water Resources Monitoring based on Big Data, No.2020GZGG026), Henan Vocational Education Teaching Reform Research and Practice Project(No. ZJA20118).

\section{REFERENCES}

[1]Cao Shuyan, Li Zhenxin. Research on the Third Party Logistics Mode of Cross Border E-commerce. E-commerce, 2013 (03): 23-25

[2]Hu Zhiying. New Ways of International Trade: the Latest Research on Cross Border E-commerce. Journal of Sichuan Cadre Correspondence College, 2017 (03): 138-140

[3]Jin Hong, Lin Xiaowei. Development Mode and Strategy Suggestions of Cross Border E-commerce in China. Macroeconomic Research, 2015 (9): 40-49

[4]Ji Fang, Zhang Xiaheng. Cross Border E-commerce Logistics Model Innovation and Development Trend. China's Circulation Economy, 2015 (06): 20-26 
Article History: Received: 28 October 2021 Revised: 05 December 2021 Accepted: 10 January 2022 Publication: 28 February 2022

[5]Wang Wailian, Wang Mingyu, Liu Shuzhen. Analysis and Suggestions on the Current Situation of Cross Border E-commerce in China. E-commerce, 2013, 000 (009): 23-24

[6]Yang Jianzheng, Yu Lu. Analysis on the Application of Cross Border E-commerce in China's Foreign Trade Enterprises. Contemporary Economic Management, 2014, 36 (006): 58-63

[7]Manual Book for Expert Pure Data for Analytics. https://www.ibm.com/cnzh/cloud/support?lnk=hpmls_busu_cnzh\&lnk2=learn

[8]He Jia. the Dilemma and Countermeasures of Cross Border E-commerce and Logistics Integration. Modern Marketing (next Issue), 2018, 000 (007): 147

[9]Wen Jing. Difficulties and Countermeasures of Cross Border E-commerce and Logistics Integration. Global Market Information Guide, 2017 (49): 14-14

[10]Jiang Youlin. Analysis on the Current Development Mode and Strategy of Cross Border Ecommerce. Business Manager, 2016 (32): 302 